\title{
ADDITIVE MANUFACTURING AND SAND-CASTING FOUNDRIES PRACTICES IN NIGERIA
}

\author{
${ }^{1}$ Adefuye, O. A.; ${ }^{1}$ Raji, N.A; . ${ }^{1}$ Adedeji, K.A; . ${ }^{1}$ Fadipe, O. L.; ${ }^{1}$ Olowu, B. \\ ${ }^{1}$ Department of Mechanical Engineering, Faculty of Engineering, Lagos State University - Epe Campus.
}

Received: 29th July, 2018

Accepted: 15th January, 2019

Published: 20th March, 2019

https://doi.org/10.47545/etrj.2019.4.1.049

\begin{abstract}
All over the developed world, the foundries have found additive manufacturing process useful and they have been incorporated into the foundry processes. In the sand-casting foundries, they are either used to produce sand moulds or used to produce patterns for sand moulding. The incorporation of the 3D printing has generally been found to increase the accuracy and quality of the castings; it has also lowered the lead time and cost of production. One of our foundries has in-house 3D printing facilities used basically for the production of patterns for sand castings, oddly, as recorded, in this foundry, the conventional method appears to perform much better than the 3D printing. This paper looks at the sand-casting practices in Nigeria and concluded that Nigerian sand casting foundries generally have to change from the low tech sand casting practices they are currently engaged in to high tech sand casting practice in order to fully benefit from additive manufacturing
\end{abstract}

Keywords: Additive Manufacturing, High technology sand casting ,casting accuracy, pattern.

\section{INTRODUCTION}

The casting process is a metal forming process whereby the metal to be cast (metal here is used to mean both pure metal and alloy) is melted and poured into a pre-prepared mould cavity. The molten metal is left to solidify and it assumes a geometry generally defined by the mould cavity. The casting is subjected to fettling and inspection after which it may be sent to the market. The advantages of casting over other metal forming process includes; (i) Material freedom. (ii) Shape freedom (iii) Size freedom sizes. (iv) Economy of production. There are many types of casting processes such as sand casting, lost foam casting, investment casting, pressure die casting, low pressure die casting, gravity die casting among others. Of all the casting processes sand casting is the oldest and the most widely used. It is also true that the vast majority of foundries in Nigeria employ sand casting process to produce the castings.

Sand casting may be appropriately described as the casting process in which the molten metal is poured under gravity into an empty sand mould. There are different genres of sand moulds depending on the binder used in the foundry sand. There are moulds made using green sand (sand that occurs naturally with binder, usually clay and moisture) and there are moulds made using synthetic sand where the binders are added to the sand. The binder determines to some extent the details of the moulding process and the properties of the mould such as the strength and its permeability and also to a large extent the dimensional accuracy of the castings produced from the process.

Pattern is the tool used to create the mould cavity and generally in sand casting the sand is compacted against the pattern which is later removed to leave the cavity into which the molten metal will be poured. Thus, pattern is the main principal tool in mould making and there can be no mould without pattern [1]

The pattern is central to the production of a good casting as error in the pattern translates automatically to resultant errors in the casting.[2]. 
Additive manufacturing (AM) is achieved by 3D printing technology; it is one of the advance manufacturing technologies which has developed rapidly in recent 30 years. It is adept at rapid and free-forming fabrication of 3D structures and widely used in new products development and production [3] It has been used in the foundry to produce sand molds and patterns. The dimensional accuracy of the patterns produced by AM is superior to that produced by the pattern maker using hand tools or non-CNC machines.

\subsection{D Printing Technology}

Though there are many printers available, only nine basic types of 3D printing technology currently exist: Fused Deposition Modeling (FDM), Stereolithography (SLA), Digital Light Processing (DLP), Selective Laser Sintering (SLS), Selective Laser Melting (SLM), Electron Beam Melting (EMB), Laminated Object Manufacturing (LOM), Binder Jetting (BJ), and Material Jetting/Wax Casting. The three most common are SLA, FDM, SLS[4]. Binder jetting technology is important to the foundry industry as it is used to build sand moulds for casting purposes.

Fused Deposition Modeling (FDM): This is currently the most popular 3D printing technology in this manufacturing process, 3D parts are produced by melting and advancing a plastic filament or metal wire through a computer-controlled extrusion nozzle. The nozzle is heated to melt the material and can be moved in both $\mathrm{x}, \mathrm{y}$ and $\mathrm{z}$ directions by a numerically controlled mechanism, directly controlled by a computer-aided manufacturing (CAM) software package [5]

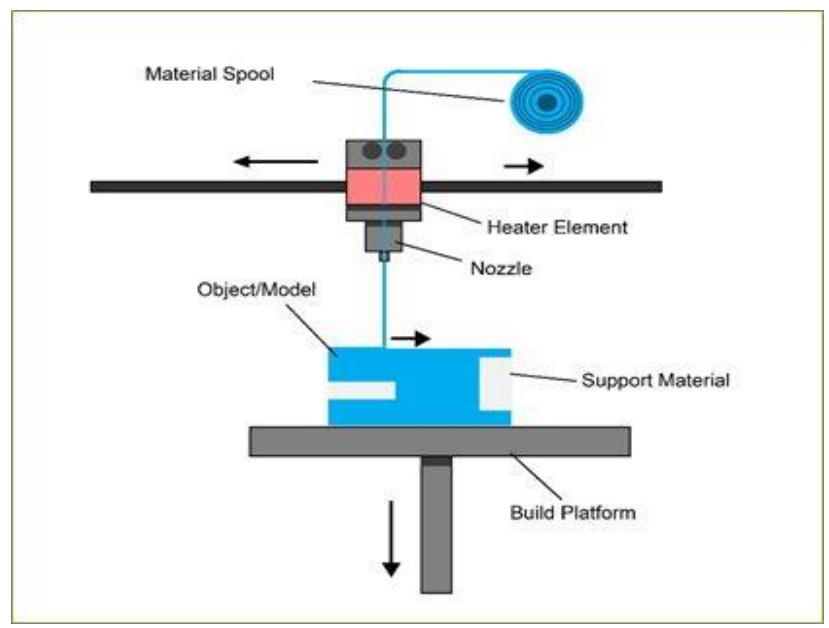

Figure1. Fused Deposition Modelling Process [19]

The model or part is produced by extruding small beads of thermoplastic material to form layers as the material hardens immediately after extrusion from the nozzle.FDM printers build objects from the bottom up and typically need support structures if the object has overhanging parts at more than a $45^{\circ}$ angle. This form of 3D printing is the most cost-effective way for individuals and small businesses to create parts quickly and efficiently [4]

Stereo-lithography (SLA): Stereo-lithography is an additive manufacturing process which employs a vat of liquid ultraviolet curable photopolymer resin and an ultraviolet laser to build parts layers one at a time [4]. The UV light solidifies the resin it touches and each layer is applied by submersion of the built platform into the resin [5]. Every standard SLA 3D printer is generally composed of four primary sections:

i). A tank filled with the liquid photopolymer: The liquid resin is usually a clear and liquid plastic.

ii). A perforated platform immersed in a tank: The platform is lowered into the tank and can move up and down according to the printing process.

iii). A high-powered, ultraviolet laser

iv). A computer interface, which manages both the platform and the laser movements

Selective Laser Sintering (SLS): Selective laser sintering is an additive manufacturing technique that uses a highpower laser (for example, a carbon dioxide laser) to fuse small particles of plastic, metal, ceramic, or glass powders into a mass that has a desired three-dimensional shape by direct laser sintering technique [5]. 
It works like other additive manufacturing technologies in that it provides a print by building layers-upon-layers until the object is complete. Once the laser traces the pattern of each layer slice into the bed of powder, the bed lowers and another layer are traced and bonded on top of the previous. A major benefit of SLS printing is that it does not require a support structure to produce intricate designs [4].

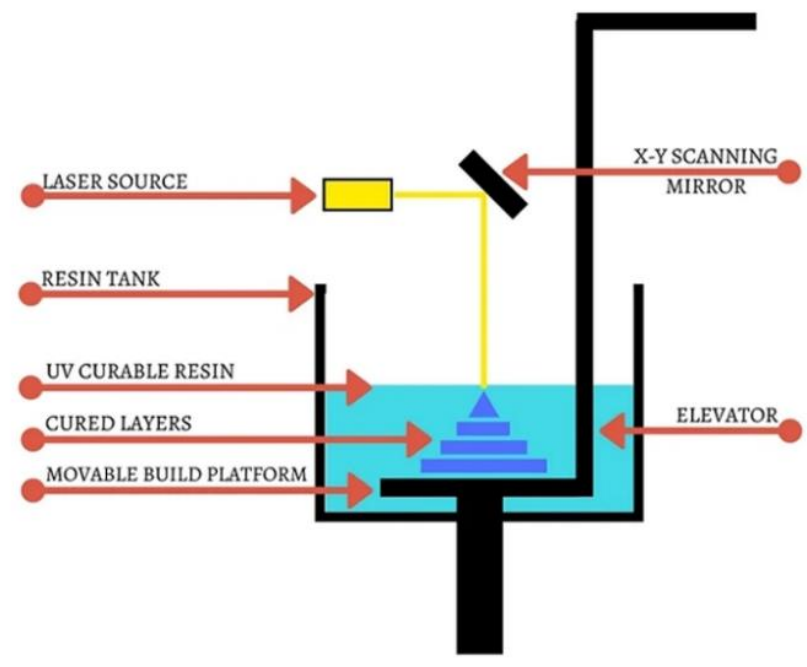

Figure 2. Stereo li-hography Process [20]

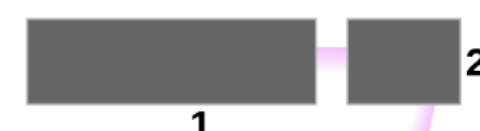

1

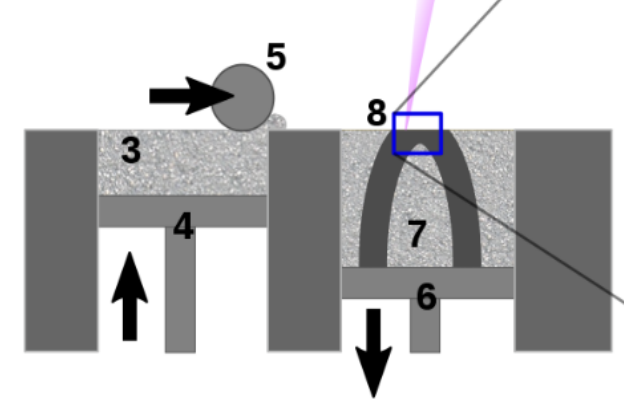

Selective laser sintering process

1 Laser $\mathbf{2}$ Scanner system 3 Powder delivery system 4 Powder delivery piston $\mathbf{5}$ Roller $\mathbf{6}$ Fabrication piston $\mathbf{7}$ Fabrication powder bed 8

Object being fabricated (see inset) A Laser scanning direction B Sintered powder particles (brown state) C Laser beam D Laser sintering E Pre-placed powder bed (green state) F Unsintered material in previous layers

Figure 3. Selective Laser Sintering Process [21]

Binder Jetting: Binder Jetting [7] is a family of additive manufacturing processes. In this process a binder is selectively deposited onto the powder bed, bonding these areas together to form a solid part one layer at a time. The materials commonly used in Binder Jetting are metals, sand, and ceramics.

Binder jetting is used to produce various things including sand casting cores and molds and the manufacture of low cost 3D metal parts. Binder Jetting process works as follows: 
i) First, a recoating blade spreads a thin layer of powder over the build platform.

ii) Then, a carriage with inkjet nozzles (which are similar to the nozzles used in desktop 2D printers) passes over the bed, selectively depositing droplets of a binding agent (glue) that bond the powder particles together. In full-color Binder Jetting, the colored ink is also deposited during this step. The size of each drop is approximately $80 \mu \mathrm{m}$ in diameter, so good resolution can be achieved.

iii) When the layer is complete, the build platform moves downwards and the blade re-coats the surface. The process then repeats until the whole part is complete.

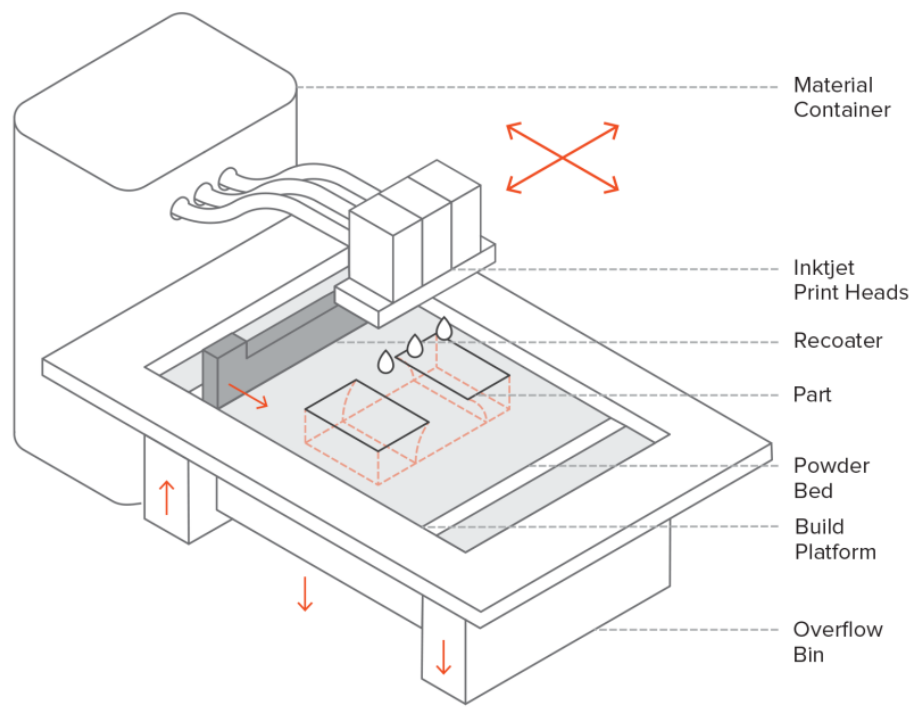

Figure 4.Jetting Binder 3D printer [7]

iv) After printing, the part is encapsulated in the powder and is left to cure and gain strength. Then the part is removed from the powder bin and the unbound, excess powder is cleaned via pressurized air. Depending on the material, a post-processing step is usually required. For example, metal Binder Jetting parts need to be sintered (or otherwise heat treated) or infiltrated with a low-melting-temperature metal (typically bronze). Full-color prototypes are also infiltrated with acrylic and coated to improve the vibrancy of colors. Sand casting cores and molds are typically ready to use after 3D printing This is because the parts are in a "green" state when they leave the printer. Binder Jetting parts in the green state have poor mechanical properties (they are very brittle) and high porosity [7]

\subsection{Materials Used in 3D Printing}

There are several materials that are used in 3D printing models. These materials are selected based on where and how the printed model will function. Some materials used includes; Poly lactic acid (PLA)filament, Acrylonitrile butadiene styrene (ABS) filament, Wood fiber filament, Polyethylene terephthalate (PET) filament, Poly vinyl alcohol (PVA) filament, Nylon filament.

Poly Lactic Acid (PLA) Filament: This material is the most common material for 3D printing. Poly lactic acid (PLA) is biodegradable thermoplastic, aliphatic polyester with molecular formula $\left(\mathrm{C}_{3} \mathrm{H}_{4} \mathrm{O}_{2}\right) \mathrm{n}$ derived from renewable resources, such as corn starch, tapioca roots or sugarcane [8].

PLA polymers range from amorphous glassy polymers to semi-crystalline and highly crystalline polymers with a glass transition temperature range of $60-65^{\circ} \mathrm{C}$, a melting temperature range of $130-180{ }^{\circ} \mathrm{C}$, and a tensile modulus 2.7-16 GPa. PLA is most suited for investment casting process method due to its low melting point temperature 
with glass transition temperature range combined with the fact that it does not produces hazardous toxics such as produced by ABS[8]

Acrylonitrile Butadiene Styrene (ABS) filament: Acrylonitrile butadiene styrene (ABS) with molecular formula $\left(\mathrm{C}_{8} \mathrm{H}_{8} \cdot \mathrm{C}_{4} \mathrm{H}_{6} \cdot \mathrm{C}_{3} \mathrm{H}_{3} \mathrm{~N}\right) \mathrm{n}$ is a common thermoplastic having transition temperature of approximately $105{ }^{\circ} \mathrm{C}$. ABS is amorphous and therefore has no true melting point[9]

ABS is a polymer made by polymerizing styrene and acrylonitrile in the presence of polybutadiene and its proportions may vary from 15 to $35 \%$ acrylonitrile, 5 to $30 \%$ butadiene and 40 to $60 \%$ styrene. For the majority of applications, ABS can be used between -20 and $80{ }^{\circ} \mathrm{C}$ as its mechanical properties vary with temperature. Its limitation is that it is less brittle than PLA, it releases hazardous fumes when heated so it is advised to keep your print area well ventilated during use [9].

Wood Fiber Filament: This is a high strength highly robust material made from wood fiber (cellulose) and typically PLA. It has the look, feel, and even the smell of natural wood[9] .The material f-used with PLA may be wood dust, cork, bamboo, or other powdered wood derivatives. Most wood filaments in the market today consist of around 60 to $70 \%$ PLA and 30 to $40 \%$ wood fibers [10].

One main reason why wood fiber filament is used is because of the superior aesthetics that it can deliver compared to standard plastic filaments. All in all, wood filaments give you prints with a wood finish without having to go through all the complexity and having all the skills needed for old-fashioned woodworking [10].

Polyethylene Terephthalate (PET) Filament: Polyethylene Terephthalate is a common material that is used to make plastic bottles, it is a versatile recyclable filament. The original state of a PET printer filament is a crystal clear and colorless material. However, when PET is heated or cooled, its transparency changes.

When the material slowly cools after using it for 3D printing, it will have a structure that is more crystalline. PET is a shockproof and hard material. It is great to use for items that are lightweight.[11].

Poly vinyl Alcohol (PVA) Filament: Poly Vinyl Alcohol (PVA) is a synthetic polymer filament formed by polymerizing vinyl acetate, which is then hydrolyzed to create PVA filaments for 3D printing. PVA filament has a translucent, white appearance. It is resistant to oil as well as grease and solvents, and has excellent adhesive properties. It has high tensile strength and flexibility

The advantage of using PVA filament is because it is soluble in water, thereby making it a good choice for creating support material which is easily removed just be placing the printed object in cold or warm water. In addition, PVA filament can be used to create water-soluble molds for ideal casting without the worry of ruining the casting when removing the mold

A comparison of the technologies and the materials employed by the different processes is illustrated by Table $1[12]$.

Patterns for Castings: The properties and functions of good patterns apart from its main function of aiding to make the mould cavity includes[13]; aiding the location of the core at its proper position, reduction of the overall cost of a casting, reduction of casting defects, aiding the creation of a parting line between the cope and the drag of the mold, simplicity in design facilitating ease of manufacture, securing the desired shape and size of casting, lightness of mass, convenient to handle and ability to withstand rough handling, possession of smooth surface, ability to resist water and moisture, retention of dimensions and rigidity during the definite service lifespan.

The materials used to fabricate patterns must be materials that will provide patterns with the needed properties and facilitate its functions. The various factors considered when choosing pattern materials include [14].

i. Method of Molding i.e. hand or machine molding.

ii. Shape, complexity and size of the casting.

iii. Types of molding material.

iv. The desired dimensional accuracy and surface finish required for the casting.

v. Casting design parameter, i.e. minimum section thickness and complexity of cast part.

vi. Nature of molding process.

vii. The number of casting to be produced. 
Some materials commonly used for creating patterns are; wood (both soft and hard), metals and alloys, plastic, plaster of Paris, wax, foams (expanded polystyrene) and resins. These materials are usually employed in creating patterns because they are; easily worked, shaped and joined, light in weight, strong, hard and durable, resistant to wear and abrasion, available at low cost, resistant to corrosion, and to chemical reactions, dimensionally stable and unaffected by variations in temperature and humidity.

In conventional sand casting the most common material used to produce patterns is wood [15].

Table 1 comparison of the different types of 3D printing technology

\begin{tabular}{|c|c|c|c|c|c|}
\hline & SLA & FDM & SLS & LOM & DLP \\
\hline Applications & $\begin{array}{l}\text { Excellent for } \\
\text { form testing Best } \\
\text { process for water } \\
\text { resistant material }\end{array}$ & $\begin{array}{l}\text { Suitable for } \\
\text { prototypes } \\
\text { Home use } \\
\text { applications }\end{array}$ & $\begin{array}{l}\text { Ideal for functional } \\
\text { parts with various } \\
\text { application } \\
\text { Suitable for } \\
\text { complex shape } \\
\text { object Heat and } \\
\text { chemical resistant }\end{array}$ & $\begin{array}{l}\text { Ideal for } \\
\text { nonfunctional } \\
\text { prototypes }\end{array}$ & Similar to SLA \\
\hline $\begin{array}{l}\text { Overall } \\
\text { Accuracy }\end{array}$ & $\begin{array}{l}\text { Most accurate } \\
\text { printing process }\end{array}$ & $\begin{array}{l}\text { Accurate and } \\
\text { reliable process }\end{array}$ & not very accurate & $\begin{array}{l}\text { Slightly less } \\
\text { dimensional } \\
\text { accuracy }\end{array}$ & High Accuracy \\
\hline Material Options & $\begin{array}{l}\text { ABS Semi- } \\
\text { flexible } \\
\text { materials High } \\
\text { temperature ABs }\end{array}$ & $\begin{array}{l}\text { Thermoplastic } \\
\text { materials }\end{array}$ & $\begin{array}{l}\text { Nylon Glass-Filled } \\
\text { Nylon }\end{array}$ & $\begin{array}{l}\text { Paper Plastic } \\
\text { Metal }\end{array}$ & Similar to SLA \\
\hline Finish Options & $\begin{array}{l}\text { Excellent } \\
\text { surface finish }\end{array}$ & Standard Finish & Standard Finish & $\begin{array}{l}\text { Wood like } \\
\text { characteristics } \\
\text { and can be } \\
\text { treated } \\
\text { similarly }\end{array}$ & $\begin{array}{l}\text { Good finish } \\
\text { High resolution }\end{array}$ \\
\hline $\begin{array}{l}\text { Post Processing } \\
\text { Requirement }\end{array}$ & $\begin{array}{lr}\text { Requires post } \\
\text { processing to } \\
\text { remove support } \\
\text { structure }\end{array}$ & $\begin{array}{l}\text { Requires post } \\
\text { processing to } \\
\text { remove support } \\
\text { structure }\end{array}$ & $\begin{array}{lr}\text { Does not require } \\
\text { support } & \text { structure, } \\
\text { less } & \text { post } \\
\text { processing requires }\end{array}$ & $\begin{array}{l}\text { Polishing } \\
\text { Painting }\end{array}$ & $\begin{array}{ll}\text { Requires } & \text { Post } \\
\text { processing } & \end{array}$ \\
\hline
\end{tabular}

\subsection{D and The Global Metal Casting Industry and Foundries in Nigeria}

Globally AM has been adopted by the foundries to produce sand moulds and patterns. The advantages of such adoption include: Faster production rate, near net shape castings, lower production cost, more flexible operations, capability to produce more complex moulds. And production of sand moulds with finer details. [16]. It is easily observed that the materials used for $3 \mathrm{D}$ is not wood, the one closest to wood is probably the wood fiber filament.

\begin{tabular}{lcc}
\hline Particulars & \multicolumn{2}{c}{ Production Lead Time (hr) } \\
& FDM Method & Conventional Method \\
\hline CAD model & 4 & 4 \\
Solid PLA pattern/ & 46 & 16 \\
Wooden pattern & & \\
Total time & 76 & 20 \\
Manpower (Nos) & 1 & 2 \\
\hline
\end{tabular}


Some faults attributable to the materials used by the AM processes for the production of pattern [2] and researches are ongoing to improve the properties of some of these materials Nigerian foundries Ltd, one of the foremost foundries in Nigeria acquired a 3D printing facility for the in-house production of patterns. An investigation into the effectiveness of the new process using the 3D facility and the former process (the conventional pattern making process) yielded the result tabulated above [2]:

As pointed out by the researchers the duration of the FDM process was over two times more than the traditional method and the only advantage in using the FDM printer is that the printer was fairly autonomous for two days while the traditional method required 8 hours per day for 2 days with human involvement. This is a pointer that changing to 3D printing also has its challenges.

\section{METHODOLOGY}

\section{Low technology and High technology Sand Casting Processes.}

The conventional sand casting process use sand moulds made with foundry sand with clay and moisture as binder. The practice in foundries in Nigeria is to use either green sand or a synthetic sand with addition of Bentonite and water as binder. There is more control on the properties of the synthetic sand than the green sand.

To prepare a two piece mould, the drag is prepared first, a flask (mould box) is placed on a moulding board and then the pattern is properly placed inside the flask, parting powder is evenly sprinkled on the surface of the pattern and the surface of the moulding board inside the flask. An appropriate amount of sand is then riddled overt the pattern and the surface of the moulding board, the sand is rammed and then another layer of sand is added and rammed, this continues until the rammed sand is a bit above the top level of the flask. A sand cutter is used to cut off the extra sand so that the level of the sand and the flask is the same. The drag is rolled over, the moulding board is removed, and another flask is placed on the drag. The process used to form the drag is repeated and the cope is formed. The cope is lifted off the drag. The pattern is then rapped to facilitate the removal of the pattern. This process may be mechanised, and different types of moulding machines have been developed and used to mould the sand, also machines are available to shake or jolt the mould to facilitate the removal of the pattern. This process automated or not is a low tech sand moulding process [18].

A no-bake moulding process uses a chemical binder that sets at the room temperature. Typically, the amount (i.e. weight) of binder is much less than the amount of clay used in the low tech binder mould and requires a sand mixer to mix it to produce a uniform blend for moulding. For parting material, patented polymer substances in pressurised cans is sprayed on the pattern's and other necessary surfaces. This quickly forms a very thin uniform layer of film over the surfaces. The layer of film is thinner, more uniform and more effective than the conventional parting powders. Flasks are used for moulding but are removed at the end of the moulding. The moulds are so strong that through the storage period, mould assembly and pouring, flasks are not needed hence the name 'flaskless process'. The moulds are also more permeable than the conventional sand moulds. There are patented pastes used to secure cores to their proper position. This reduces the need of elaborate core prints. However, in order to recycle the sand used for moulding the moulds may have to be heated up to cause the binder to lose its strength. This is the high tech sand casting process.

One difference in the two processes is the dimensional accuracy achievable with each process. These are intrinsic to each process and the paper by [18] Campbell explains the reason in some details. It indicates that when there is no dimensional error attributable to the pattern, the maximum variability in a meter long casting produced by the low tech sand casting is $0.13 \%$ and that of a casting produced by a high tech sand casting process is $0.04 \%$. Figures 5 and 6 shows that while dimensional accuracy of the high tech sand casting is one of the best obtainable by any casting process competing favourably with the so called precision processes such as lost wax process and pressure die casting. The Figures however shows that the dimensional accuracy of low tech sand casting is the worst 


\section{RESULTS AND DISCUSSION}

The Practice in the Foundries in Nigeria: In Nigeria like it is globally, sand casting is the most popular process and no less than $90 \%$ of our foundries practice sand casting. A vast majority of the foundries practice low tech. sand casting and they use no-bake binders only when they have to produce cores. Even then, they use either furan (which is toxic) or sodium silicate and not patented binders specifically made for the production of sand mould. This would not make them achieve a near net shape product even if they got the pattern made to precision using the services of a 3D facility provider.

If the sand casting foundries in Nigeria are to derive full benefits of the 3D technology facilities locally available, they will need to use a 3D facility to produce the pattern to precision and produce the sand moulds using high tech sand moulding process.

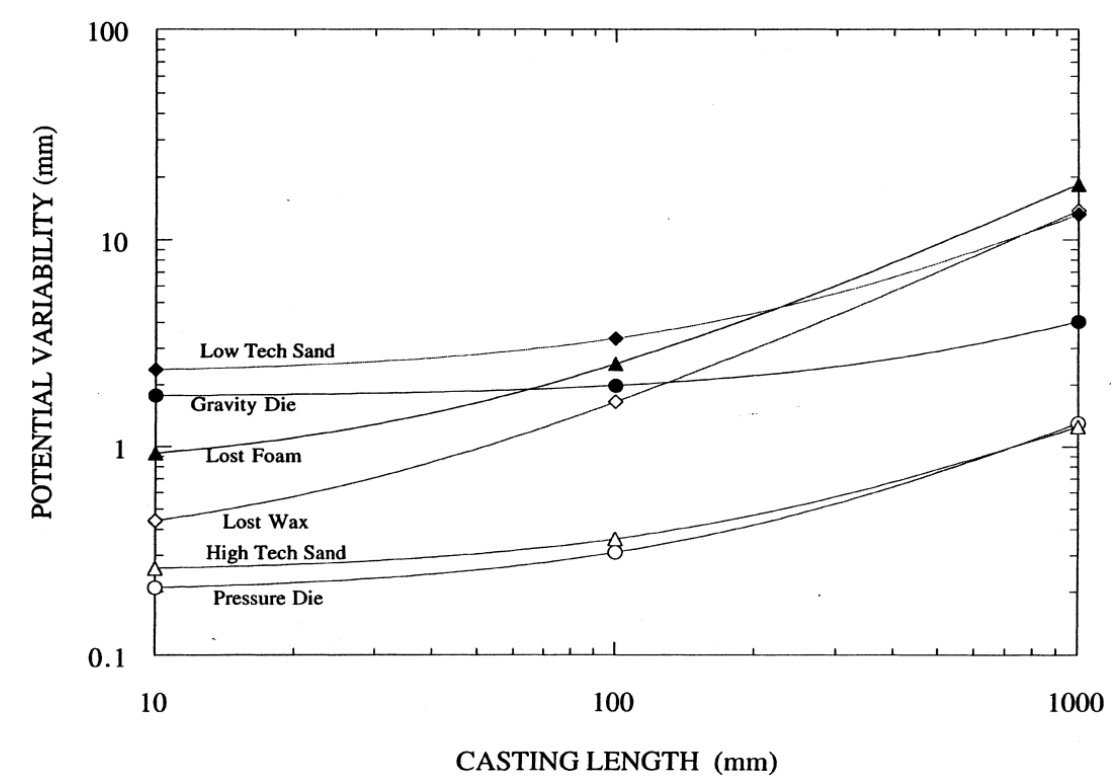

Figure 5 Graph of casting length (mm) vs potential variability (mm). [18]

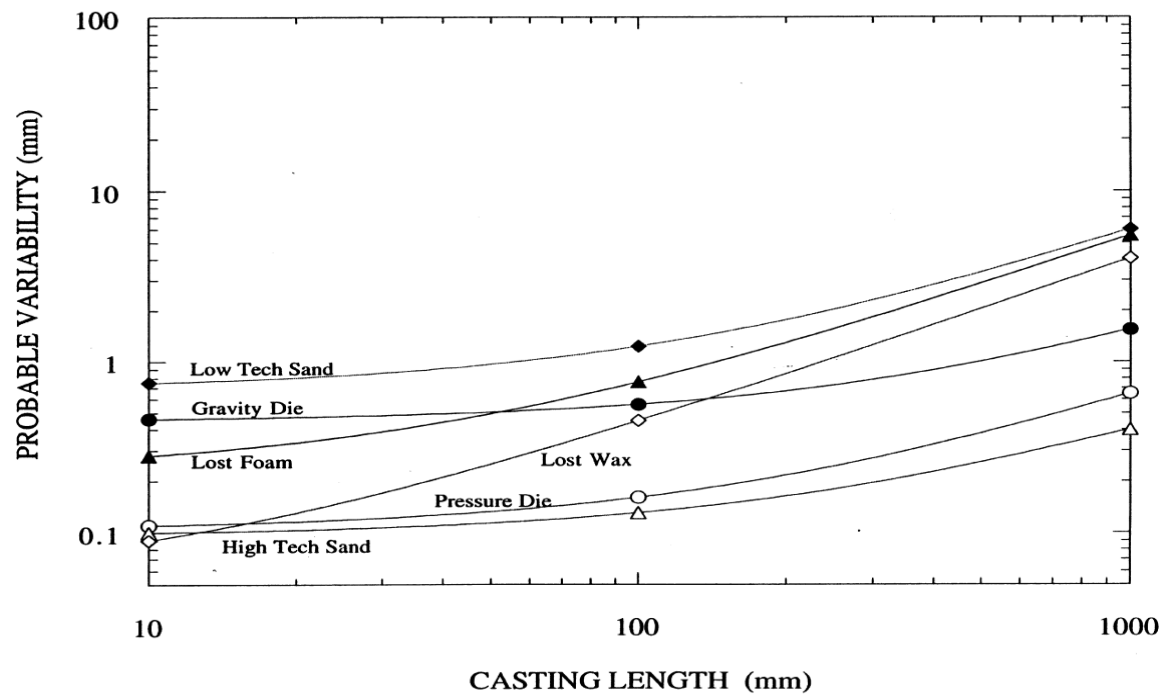

Figure 6 Graph of casting length $(\mathrm{mm})$ vs probable variability $(\mathrm{mm})[18]$ 


\section{CONCLUSION}

(i) Conventional sand casting cannot produce near net shape casting even if the pattern has accurate dimensions.

(ii) Near net shape castings can be produced using no-bake binders for the foundry sand.

(iii) Near net shape castings can also be produced from moulds built using AM processes.

(iv) In order to take full advantage of 3D facilities available, foundries in Nigeria should engage in high tech sand moulding.

\section{REFERENCES}

[1] Shaktawat, N., \& Patel, C. M. (2018). Design, Analysis and Modification in Pattern Design Using the Combination of Aluminium and Acrylic Parts in Wooden Pattern. Journal of Experimental \& Applied Mechanics, 8(2), 13-32.

[2] Anakhu, P. I., Bolu, C. A., Abioye, A. A., Azeta J (2018) Fused Deposition Modeling Printed Patterns for Sand Casting in a Nigerian Foundry: A Review International Journal of Applied Engineering Volume 13, Number 7 pp. 5113-5119

[3] Bingheng, L. U., \& Dichen, L. I. (2013). Development of the additive manufacturing (3D printing) technology. Machine Building \& Automation, 4, 001.sign, 21(4), 373-380.

[4] MakeShaper makeshaper.com

[5] Domain group 3D 3D Printing.pdf - Domain Group 3D Printing Workshop Notes 1 www.coursehero.com $>$ file

[6] Erik Sætre - Development of Additive Manufacturing Technology, Implications on the design process and the transportation industry, moving from prototyping to productionNorwegian University of Science and Technology. www.ntnu.no>ErikArtikkel.pdf.

[7] Varotsis A. B. https://www.3dhubs.com/knowledge-base/introduction-binder-jetting-3d-printing/

[8]. Mendonsa, C., \& Shenoy, V. D. (2014). Additive manufacturing technique in pattern making for metal casting using fused filament fabrication printer. Journal of Basic and Applied Engineering Research, 1(1), 10-13

[9] ALT LLC www.3dalt.com

[10]Flynt J,( 2018.) "Wood Filament: Properties, How to Use Them, and Best Brands", 3DINSIDER, 3dinsider.com

[11] All that 3D www.allthat3d.com

[12] Jasveer, S., \& Jianbin, X. (2018). Comparison of different types of 3D printing technologies. International Journal of Scientific and Research Publications (IJSRP), 8(4), 1-9.

[13] Sibi, J (2017) . PPT on Types of Pattern , https://www.slideshare.net/jerinsibi/ppt-on- types-ofpattern?qid=d9486c0f-1eec-4a8c-b1ee-909fdca238d5\&v=\&b=\&from search=1

[14] Purohit, R. K. (2005 ). Materials Science and Processes, Scientific Publishers Journals Department

[15] Singh, A. K. (2018) Basic Manufacturing Processes, Educreation Publishing,

[16] UPADHYAY M, SIVARUPAN T, MANSORI , M ( 2017) - 3D printing for rapid sand casting-A review,Journal of Manufacturing Processes - Vol. 29, p.211-220

[17] Malagi, R. R., Mahendra, S. B., Pol, A., \& Raikar, P. (2014). Development of casting pattern using rapid prototyping. International Journal of Research in Engineering and Technology, 3(6), 277-280

[18] Campbell, J. (2000). The concept of net shape for castings. Materials \& Design, 21(4), 373-380

[19] Fused deposit modeling(IFDM),. The Technology House \{online\}, https:/www.tth.com/£d-printing/fdmprototyping/.

[20] How Stereolithography (SLA) 3D Printing Works, (2018), Manufactur3D, Retrieved from https://manufactur3dmag.com/stereolithography-sla-3d-printing-works/

[21] Elizabeth Palermo, ${ }^{\wedge}$ What Is Selective Laser Sintering? Live Science [Online]. 